\title{
USO DO ADESIVO DE FIBRINA NAANASTOMOSE ESÔFAGO-ESOFÁGICA CERVICAL, EM CÃES
}

\author{
THE USE OF FIBRIN ADHESIVE IN THE ESOPHAGUS-ESOPHAGEAL CERVICAL \\ ANASTOMOSIS, IN DOGS
}

\author{
Orlando Ribeiro Prado Filho, TCBC-PR' ${ }^{1}$; Djalma José Fagundes, TCBC-SP²; \\ Amaury José Teixeira Nigro, TCBC-SP ${ }^{3}$; César Orlando Peralta Bandeira, ACBC-PR ${ }^{1}$; \\ Neil Ferreira Novo ${ }^{4}$, Yara Juliano ${ }^{4}$
}

\begin{abstract}
RESUMO: Objetivo: Estudar os efeitos da associação do adesivo cirúrgico de fibrina à técnica operatória da invaginação submucosa, em anastomoses esofagianas. Método: Trinta e dois cães submetidos à anastomose esôfago-esofágica foram alocados em dois grupos: I com sutura em doze pontos e II com sutura em quatro pontos e vedação com adesivo de fibrina. Os animais foram avaliados no sétimo e décimo-quarto dias de pós-operatório. Foram analisados: a evolução ponderal, o índice de estenose, a incidência de deiscências e fístulas, a presença de secreções na tela subcutânea, a presença de líquido intersticial, matriz protêica, celularidade, fibroblastos, fibras de colágeno e concentração de hidroxiprolina. Resultados: O índice de estenose foi menor para os animais do grupo I no sétimo dia de observação. Nos animais do grupo II a incidência de deiscências, secreção serosa e purulenta foram signitivamente maiores aos sete e quatorze dias, enquanto a presença de fístulas foi maior no sétimo dia. Quanto à concentração tecidual de hidroxiprolina não houve diferença estatística entre os grupos. Os fibroblastos e fibras de colágeno tiveram presença mais acentuada no grupo II no décimo-quarto dia. Ocorreram quatro óbitos em animais do grupo II. Conclusão: A anastomose por invaginação submucosa-mucosa com vedação com adesivo de fibrina apresentou piores resultados que a anastomose convencional de doze pontos circunferenciais.
\end{abstract}

Descritores: Anastomose Cirúrgica; Cães; Adesivo de Fibrina; Esôfago.

\section{INTRODUÇÃO}

As anastomoses no tubo digestório obedecem a alguns princípios técnicos fundamentais. A técnica operatória de reconstrução do trânsito alimentar deve permitir que a anastomose seja continente, pérvia, não propiciar isquemia na linha de sutura, afrontar as bordas da cicatriz sem causar estenose, produzir a menor intensidade de aderências possível e respeitar a integridade visceral ${ }^{1,2}$.

Vários tipos de materiais e técnicas foram idealizados para tornar a anastomose do tubo digestório mais segura e eficaz. Fios cirúrgicos mais resistentes e inertes, com menor capacidade de desencadear reação inflamatória, tais como o ácido poliglicólico, a poliglactina 910 e o polipropileno $^{3}$; grampeadores para sutura mecânica ${ }^{4}$; anéis biofragmentáveis ${ }^{5}$ e $\operatorname{adesivos}^{6,7}$ têm sido usados contemporaneamente.

Dentre os adesivos destaca-se o de fibrina, uma substância formada pelo fibrinogênio humano e aprotinina aos quais são acrescentados a trombina e o cloreto de cálcio. Ela contribui favoravelmente para a cicatrização da ferida por produzir hemostasia local e estimular o fluxo de macrófagos com produção de fatores que favorecem a angiogênese, a proliferação de fibroblastos e a produção de colágeno ${ }^{7}$. Ou- tros trabalhos experimentais, entretanto, mostraram resultados insatisfatórios, como o aumento da reação inflamatória e o retardo na cicatrização de anastomoses intestinais ${ }^{8-10}$.

Nigro $^{11}$, com o objetivo de reduzir a morbimortalidade relacionada com as deiscências de suturas e fístulas, idealizou procedimento cirúrgico que consiste na invaginação de uma porção de submucosa-mucosa do coto esofágico cranial dentro da luz do coto distal. Comparou-a com as técnicas de sutura em plano único extramucoso e em dois planos, em anastomoses esôfago-esofágicas término-terminais cervicais em cães. Os resultados da nova técnica mostraram-se superiores às anteriores.

Seguindo esta linha de pesquisa, Polonio ${ }^{12}$ ratificou os bons resultados da técnica de anastomose por invaginação submucosa-mucosa no esôfago cervical de cães, usando o anel biofragmentável de ácido poliglicólico. Calomeno ${ }^{13} \mathrm{e}$ Prado Filho ${ }^{14}$ também obtiveram melhores resultados com a técnica proposta, usando como comparação, respectivamente, um tubo de dura-máter canina externo à anastomose ou tubo de borracha maleável interna à mesma.

O objetivo deste trabalho foi estudar aspectos morfológicos da cicatrização da anastomose esôfagoesofágica cervical por invaginação com o uso do adesivo de fibrina, em cães.

1. Professor Adjunto da Área de Clínica Cirúrgica do Departamento de Medicina da Universidade Estadual de Maringá - Maringá - PR.

2. Professor Adjunto da Disciplina de Técnica Operatória e Cirurgia Experimental do Departamento de Cirurgia da Universidade Federal de São Paulo - Escola Paulista de Medicina (UNIFESP-EPM).

3. Professor Titular Aposentado da Disciplina de Técnica Operatória e Cirurgia Experimental do Departamento de Cirurgia da UNIFESP-EPM.

4. Professor Adjunto da Disciplina de Bioestatística do Departamento de Medicina Preventiva da UNIFESP - EPM

Recebido em 18/02/2003

Aceito para publicação em 14/10/2003

Trabalho realizado na Disciplina de Técnica Operatória e Cirurgia Experimental - UNIFESP-EPM e Departamento de Medicina da Universidade Estadual de Maringá-PR. 


\section{MÉTODO}

Foram utilizados 32 cães mestiços, de ambos os sexos, adultos, com peso entre oito e $12 \mathrm{Kg}$, provenientes do canil do Biotério Central da Universidade Estadual de Maringá (UEM), onde permaneceram em observação nos períodos pré e pós-operatórios. Os procedimentos foram aprovados pelo Comitê de Ética em Pesquisa do Hospital São Paulo da Universidade Federal de São Paulo-Escola Paulista de Medicina (UNIFESP-EPM).

Os animais foram distribuídos aleatoriamente em dois grupos de 16 cães e redistribuídos em dois subgrupos (Figura 1). Foram mantidos em jejum completo nas seis horas que antecederam a operação. A indução anestésica foi realizada com solução de xilazina $2 \%$ na dose de $3 \mathrm{mg} . \mathrm{Kg}^{-1}$ de peso, por via intramuscular e a manutenção com tiopental sódico $2,5 \%$ por via endovenosa, na dose de $5 \mathrm{mg} \cdot \mathrm{Kg}^{-1}$ de peso $^{14}$. Foram mantidos com ventilação pulmonar espontânea durante o ato operatório.

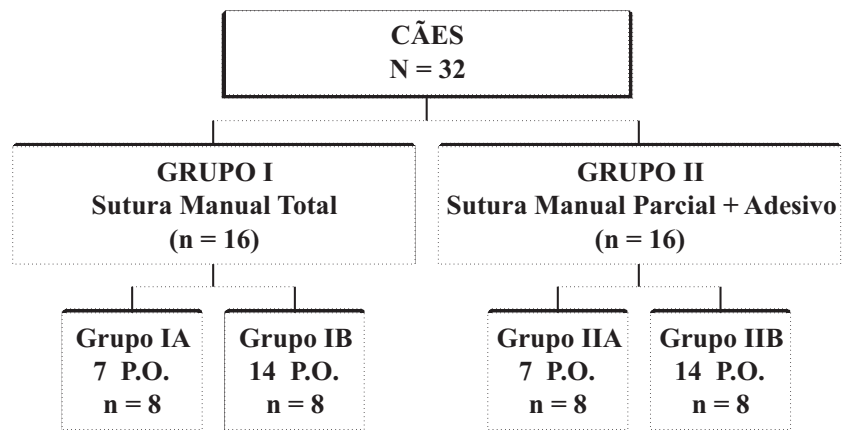

Figura 1 - Esquema da distribuição dos animais nos diversos grupos e subgrupos do estudo, segundo o tipo de aproximação dos cotos e tempo de observação no período pós-operatório.

Foi realizada incisão longitudinal de $5 \mathrm{~cm}$ de comprimento na linha média ventral da região cervical e o esôfago foi identificado e isolado. Foram realizadas duas incisões nas túnicas adventícia e muscular do esôfago em toda a sua circunferência e distantes $2 \mathrm{~cm}$ entre si, ficando mantidas intactas as camadas submucosa e mucosa. Esse segmento foi descolado da submucosa-mucosa por dissecção romba. O anel resultante dessa dissecção foi então seccionado e retirado, deixandose um segmento de submucosa-mucosa íntegro mantendo o trajeto esofágico cervical. Junto à borda caudal foi seccionado o segmento de submucosa-mucosa, ficando um tubo em continuidade com a parte cranial do esôfago cervical (Figura 2A, $2 \mathrm{~B}, 2 \mathrm{C}$ ).

Nos animais do grupo I foi realizada a anastomose esôfago-esofágica término-terminal com invaginação do segmento de submucosa-mucosa no coto caudal. A fixação da camada adventícia-muscular dos cotos foi realizada pela aplicação inicial de quatro pontos eqüidistantes com fio de poliglecaprone $25^{*}$, monofilamentar $4-0$ em agulha cilíndrica (*Monocryl@ Ethicon) e posteriormente intercalado com outros dois pontos entre eles, totalizando 12 pontos em toda a circunferência da linha anastomótica (Figura 2D). Todos os pontos foram confeccionados em plano único extramucoso e com os nós voltados para a face da adventícia do esôfago.
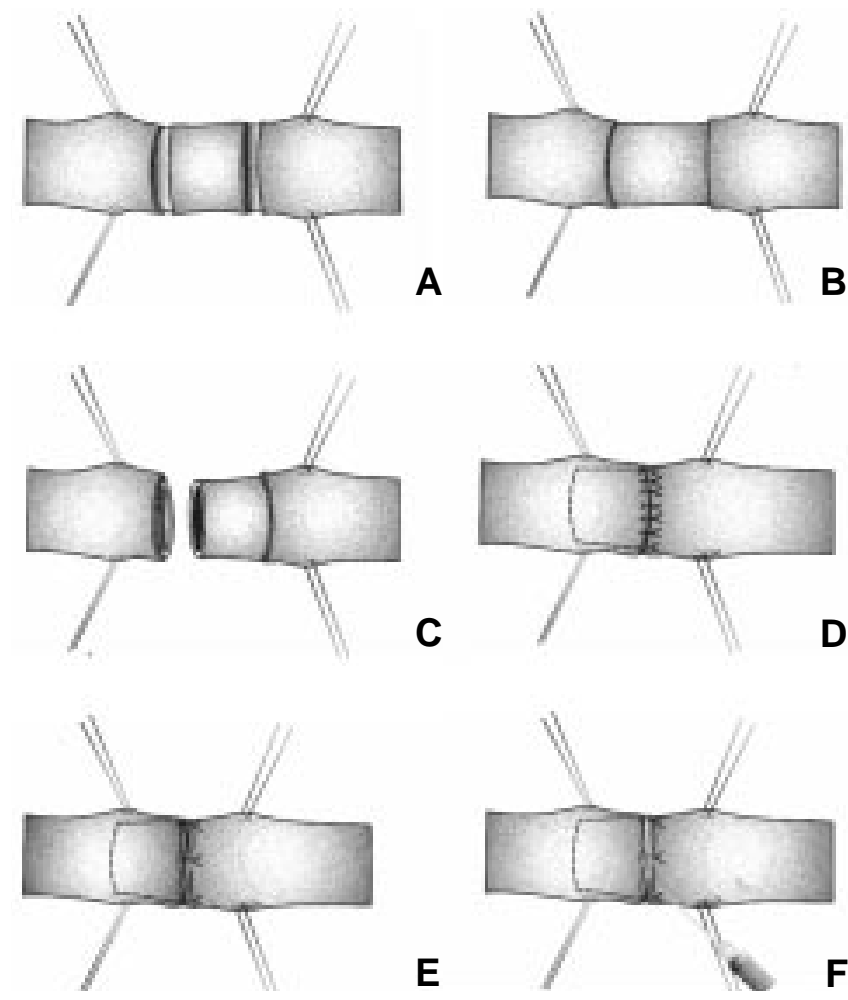

Figura 2 - Desenhos esquemáticos que apresentam a seqüência da técnica operatória de invaginação submucosa-mucosa para os grupos $I(D)$ e II $(F)$.

Nos animais do grupo II também foi realizada a anastomose esôfago-esofágica término-terminal com invaginação do segmento de submucosa-mucosa no coto caudal. A fixação da camada adventícia-muscular dos cotos foi realizada pela aplicação inicial de quatro pontos eqüidistantes com fio de poliglecaprone 25, monofilamentar 4-0 em agulha cilíndrica (Figura 2E). Para complementação da aproximação dos cotos foi aplicada $0,5 \mathrm{~mL}$ do adesivo de fibrina (Beriplast ${ }^{\circledR}$ $\mathrm{P}$ Centeon Farmacêutica) na circunferência da linha de anastomose (Figura 2F).

Do primeiro ao terceiro dia P.O. os animais foram mantidos com dieta líquida e a partir do quarto dia iniciouse dieta sólida industrializada. Foram reoperados nas data previamente estabelecidas para os dois grupos. Seccionouse um segmento da porção cervical do órgão, numa extensão de $10 \mathrm{~cm}$, que incluísse a região da anastomose. $\mathrm{O}$ abate foi praticado mediante injeção endovenosa de $20 \mathrm{~mL}$ de solução de cloreto de potássio a $19,1 \%$. Os animais que morreram antes do dia da avaliação foram substituídos, para que os grupos apresentassem número correspondente de espécimes para avaliação.

Durante a reoperação, foram observadas as condições macroscópicas da ferida e da peça operatória. O grau de estenose foi avaliado pela medição, dos comprimentos transversais internos do esôfago em centímetros, com a peça aberta, da mesma forma que Prado Filho et $a l^{14}$. Para o estudo da concentração do colágeno na anastomose, dosou-se a concentração de hidroxiprolina tecidual no Laboratório de Inflamação do Departamento de Farmácia e Farmacologia da Universidade Estadual de Maringá. 
A avaliação histológica das peças operatórias foi realizada por digitalização de imagens pelo programa Image-ProPlus versão 4.01 - Média Cibertecnics de análise gráfica, no Laboratório de Microscopia do Departamento de Ciências Morfológicas da Universidade Estadual de Maringá.

Foram utilizados: o teste "t" de Student; o teste de Mann-Whitney, a análise de variância por postos de KruskalWallis, o teste do Quiquadrado. Quando foram detectadas as restrições de Cochran, o teste exato de Fisher foi usado. O nível de rejeição da hipótese de nulidade foi fixado em $0,05 \mathrm{ou}$ $5 \%(\alpha \leq 0,05)$.

\section{RESULTADOS}

Houve redução dos pesos dos animais em ambos os grupos, porém, estas variações não foram significativas tanto no $7^{\circ}$ quanto no $14^{\circ}$ dia pó-operatório. Houve significância estatística quando se avaliou os valores dos índices de estenose dos grupos I e II no $7^{\circ}$ dia P.O., com menor redução do diâmetro da anastomose nos animais do primeiro grupo. Não houve diferença significante na observação realizada no $14^{\circ}$ dia.

Em relação à presença de coleção líquida na tela subcutânea, não houve diferenças dentro dos grupos. A presença de coleção purulenta na tela subcutânea ocorreu no grupo II $(6,2 \%)$, porém sem que houvesse significância estatística.

No grupo I não houve ocorrência de fístulas, deiscências ou óbito de animais. Nos animais do grupo II, a incidência de deiscência e óbito foi de $20 \%$. As mortes ocorreram entre o segundo e o quinto dia pós-operatório, razão pela qual houve a substituição de quatro animais. No grupo II ocorreu maior frequiência de casos da presença de secreção purulenta na região perianastomótica.

Não houve diferença significante quanto à concentração tecidual de hidroxiprolina entre os grupos. Quando se fez a comparação dentro do grupo, observou-se que no grupo II a concentração tecidual de hidroxiprolina no $14^{\circ}$ dia foi estatisticamente maior que no $7^{\circ}$ dia P.O.. No grupo I não houve diferença significante no $7^{\circ}$ e $14^{\circ}$ dias.

Com relação ao edema inflamatório, entre os grupos, no $7^{\circ}$ ou $14^{\circ}$ dia de P.O., ou entre os subgrupos do mesmo grupo, não ocorreu diferença estatística. Sobre a matriz protêica tecidual, na comparação entre os grupos, percebeu-se uma diferença significante tanto no $7^{\circ}$ quanto no $14^{\circ}$ dia de P.O., em ambos os casos, o pior resultado observado nos animais do grupo I.

A presença de núcleos celulares foi estatisticamente maior nos animais do grupo I no $7^{\circ}$ dia de observação, em comparação com os animais dos grupo II e não houve diferença no $14^{\circ}$ dia. A fibroplasia mostrou-se reduzida nos animais do grupo II ao final da segunda semana.

\section{DISCUSSÃO}

A sutura com fio é ainda o método mais utilizado para a aproximação das bordas da ferida operatória. Há vários materiais disponíveis no mercado e sua indicação depende do tecido a ser suturado ${ }^{15}$.
Apesar do adesivo de fibrina ter sido objeto de trabalhos experimentais e clínicos em vários tipos de anastomoses, ainda há dúvidas da indicação do seu uso em segmentos do tubo digestório com maior risco de deiscência, por exemplo no esôfago ${ }^{7,8,10,15}$. McCarthy et al. ${ }^{16}$ foram os únicos a realizar experimento com adesivo de fibrina em anastomose esôfago-gástrica em cães e chegaram à conclusão que ela previne deiscências.

$\mathrm{O}$ adesivo de fibrina é composto por dois componentes, que misturados, resultam em um vedante. O fibrinogênio é a maior porção do primeiro componente, que também contém o fator XIII e proteínas plasmáticas. O segundo componente consiste em trombina, cloreto de cálcio e aprotinina (agente antifibrinolítico). A aprotinina previne a lise prematura do coágulo de fibrina e a trombina converte fibrinogênio em fibrina, dando início ao processo de solidificação da solução. Na presença do cloreto de cálcio, a trombina ativa a fator XIII que catalisa a formação das ligações da fibrina, o que intensifica a força tênsil do coágulo? .

As ações hemostática, vedante, adesiva, promotora de cicatrização e anti-séptica da fibrina lhe conferem um grande número de aplicações em todas as especialidades cirúrgi$\operatorname{cas}^{7,15}$. Vários autores utilizaram-na como complemento em suturas do intestino delgado ${ }^{7,10}$ e grosso ${ }^{8-10} \mathrm{com}$ resultados conflitantes quanto à sua eficiência na proteção das anastomoses.

$\mathrm{Na}$ anastomose esôfago-esofágica por invaginação, ao introduzir um segmento tubular proximal de submucosamucosa de dois centímetros do esôfago cranial na sua porção caudal (Figura 3), ocorre dificuldade de contato da linha de sutura com as secreções digestivas e alimentos, o que facilita os processos iniciais de cicatrização ${ }^{11}$.
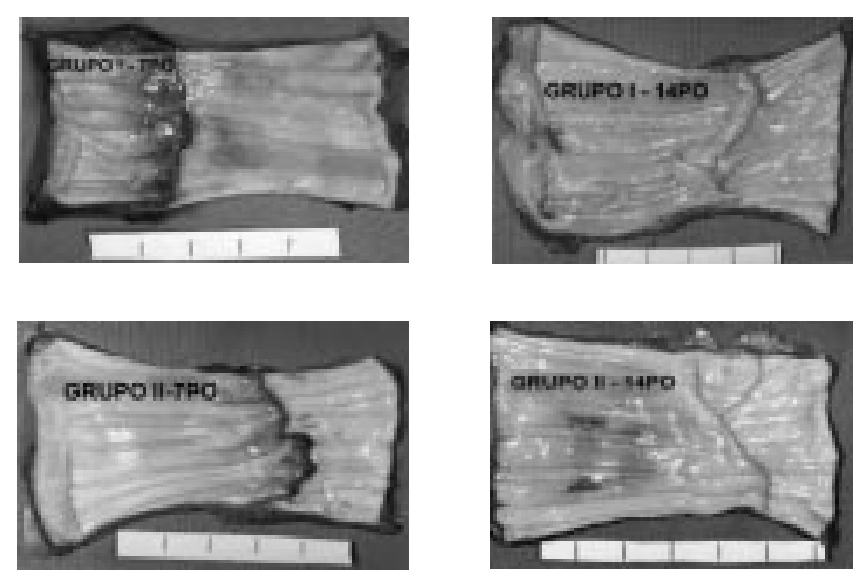

Figura 3 - Anastomoses esôfago-esofágicas por invaginação observadas no $7^{\circ}$ e $14^{\circ}$ PO. Nota-se o aspecto típico do segmento de submucosa-mucosa sobre a linha de sutura.

É importante ressaltar que a freqüência de processo infeccioso e óbito foi maior nos animais com adesivo biológico. Aparentemente o adesivo de fibrina foi um fator que piorou a evolução dos animais no período pós-operatório, pois a sua presença foi a causa provável das complicações infecciosas e das falhas de cicatrização das suturas encontradas no terceiro grupo. 
Vários autores ${ }^{15,17,18}$ têm referido que o adesivo de fibrina pela sua composição poderia ser um fator favorável para o desenvolvimento de infecção, principalmente em situações de procedimentos contaminados. Isto está em concordância com o achado de secreção purulenta na cavidade cervical apenas nos animais do grupo II (18,7\%), porém sem que houvesse significância estatística. Nesse sentido, mostra-se coerente a utilização de antibioticoprofilaxia para se reduzir risco de infecção pelo uso do adesivo de fibrina.

A hidroxiprolina é um aminoácido que corresponde a $14 \%$ da quantidade do colágeno total ${ }^{17}$ e há uma relação direta entre ela e a cicatrização da anastomose ${ }^{18}$. Neste experimento as diferenças não foram significantes.
Como em outros trabalhos ${ }^{7,15}$, o adesivo biológico propiciou uma menor reação inflamatória (número de células inflamatórias) e formação de tecido cicatricial, em ambas fases de observação.

A matriz protêica é uma estrutura complexa e com ligações cruzadas de proteínas e polissacarídeos que circundam as células e organiza a geometria dos tecidos. O colágeno é o seu principal elemento ( $25 \%$ do total), sendo um componente crucial em todas as fases do reparo da ferida ${ }^{19}$. Os resultados demonstram que, em termos microscópicos, as anastomoses nos animais do grupo I apresentavam menor concentração de colágeno no líquido extracelular.

Concluindo, o resultados das anastomoses esôfagoesofágicas por invaginação, com uso do adesivo de fibrina, mostraram-se inferiores aos das anastomoses com fio de sutura.

\begin{abstract}
Background: The aim of this research was to study the effects of the use of fibrin adhesive with the surgical technique of submucosa invagination, in esophageal anastomosis. Methods: Thirty two dogs operated on for esophageal anastomosis, were distributed in two groups: group I with encircling suture of twelve stitches, and group II with encircling suture of four stitches and fibrin sealant. The anastomosis was evaluated in the $7^{\text {th }}$ and $14^{\text {th }}$ post-operative day. Weight evolution, stenosis rate, presence of dehiscence and fistulae, presence of secretion around the anastomosis, presence of interstitial liquid, protean matrix, number of cells, fibroblasts, collagen fibers and the hydroxyproline concentration in the anastomosis were analysed. Results: The stenosis rate was lower in the group I in the $7^{\text {th }}$ post-operative day. The incidence of fistulae was significant in group II on the $7^{\text {th }}$ day, as well as the presence of dehiscence, serosa secretion and suppurative secretion at the $7^{\text {th }}$ and $14^{\text {th }} d a y$. Concerning hydroxyproline tissue concentration there was no statistical difference among the groups. The fibroblasts and collagen fibers were more numerous in group II at $14^{\text {th }}$ day. There were four deaths in animals of group II. Conclusion: We concluded that anastomosis performed by submucosa-mucosa invagination with fibrin adhesive presented results less satisfactory than anastomosis performed with twelve encircling stitches.
\end{abstract}

Key Words: Dogs; Esophagus; Fibrin adhesive; Surgical anastomosis.

\section{REFERÊNCIAS}

1. Fagundes DJ, Goldenberg S - "Princípios gerais de hemostasia, suturas e anastomoses”. In Jorge Filho I, Andrade JI, Zillioto Jr A (eds) - Cirurgia geral. Pré e pós-operatório. $1^{\text {a }}$. Edição. São Paulo. Atheneu, 1995, pp. 79-87.

2. Nigro AJT - "Anastomoses digestivas". In Souza VT (ed) Coloproctologia. 2a' Edição. Rio de Janeiro. Medsi, 1999.

3. Fagundes DJ, Kharmandayan P - O fio cirúrgico. Acta Cir Bras, 1991, 6(3):177-181.

4. Steinchen FM, Ravitch MM - Instrumentos de grampeamento contemporâneo e técnicas básicas de sutura mecânica. Clin Cir Am Norte, 1984, 3: 445-462.

5. Hardy TG, Pace WG, Maney JW, et al. - A biofragmentable ring for sutureless bowel anastomosis. An experimental study. Dis Colon Rectum, 1985, 28(7):484-490.

6. Biondo-Simões MLP, Vivi AAG, Fagundes DJ - Adesivos em anastomoses do trato digestivo. Acta Cir Bras, 1993, 8(1):41-44.

7. Sousa C - Uso de adesivos biológicos em anastomoses intestinais - estudo experimental em coelhos. Dissertação (Doutorado em Medicina). Belo Horizonte. Universidade Federal de Minas Gerais, 1993, 202 p.

8. van der Ham AC, Kort WJ, Weijma IM, et al. - Transient protection of incomplete colonic anastomoses with fibrin sealant: an experimental study in the rat. J Surg Res, 1993, 55(3):256260.

9. van der Ham AC, Kort WJ, Weijma IM, et al. - Effect of fibrin sealant on the integrity of colonic anastomoses in rats with faecal peritonitis. Eur J Surg, 1993, 159(8):425-432.
10. Shinohara K, Kobayashi E, Yoshida T et al. - Effect of fibrin glue on small and large bowel anastomoses in the rat. Eur Surg Res, 1997, 30(1):8-12.

11. Nigro AJT - Anastomoses esôfago - esofágicas cervicais término-terminais em dois planos de sutura, em plano único extramucoso e por invaginação: estudo comparativo experimental em cães. Dissertação (Livre Docência). São Paulo. Universidade Federal de São Paulo. 1990.

12. Polonio B - Anastomoses esôfago-esofágicas cervicais término-terminais por invaginação e com anel biofragmentável: estudo comparativo em cães. Dissertação (Doutorado em Medicina). São Paulo. Universidade Federal de São Paulo. 1994.

13. Calomeno JGA - Comparação, em cães, das anastomoses esôfago-esofágicas cervicais término-terminais envolvidas externamente por uma faixa de dura-máter homóloga e as por invaginação. Dissertação (Doutorado em Medicina). São Paulo. Universidade Federal de São Paulo. 1995.

14. Prado Filho OR, Nigro AJT, Bandeira COP, et al. - Eficácia do tubo de borracha como revestimento interno em anastomoses esôfago-esofágicas em cães. Acta Scientiarum, 1999, 21:389393.

15. Spotnitz WD, Falstrom JK, Rodeheaver GT - The role of sutures and fibrin sealant in wound healing. Surg Clin North Am, 1997, 77(3):651-669.

16. McCarthy PM, Trastek VF, Schaff HV, et al. - Esophagogastric anastomoses: the value of fibrin glue in preventing leakage. J Thorac Cardiovasc Surg, 1987, 93(2):234-239. 
17. Uzunkoy A, Akinci OF, Coskun A, et al - Effects of antiadhesive agents on the healing of intestinal anastomosis. Dis Colon Rectum, 2000, 43(3):370-375.

18. Ertekin C, Kurdoglu M, Ozgur M, et al. - The healing of intestinal anastomosis and the effect of suture materials. Turk $\mathbf{J}$ Surg, 1989, 5(1):31-34.

19. Adzick NS - "Cicatrização da ferida". In Sabiston Jr DC, Lyerly HK (eds) - Tratado de cirurgia. Rio de Janeiro. Guanabara Koogan, 1999.
Endereço para correspondência: Dr. Orlando Ribeiro Prado Filho Rua Silva Jardim, 560

87013-010 - Maringá - PR

E-mail: família@wnet.com.br 